\title{
Lymphatic Drainage of the Cranial Thoracic Mammary Gland in the Domestic Cat
}

\author{
Cristian DEZDROBITU ${ }^{1 *}$, Ionel PAPUC ${ }^{2}$, Melania CRIȘAN ${ }^{1}$, Irina IRIMESCU ${ }^{1}$, Alexandru GUDEA ${ }^{1}$, Ioana \\ DUMITRU $^{1}$, Cristian MARTONOS ${ }^{1}$, Aurel DAMIAN ${ }^{1}$ \\ ${ }^{1}$ Department of Comparative Anatomy, Faculty of Veterinary Medicine, University of Agricultural Sciences \\ and Veterinary Medicine Cluj-Napoca, Romania \\ ${ }^{2}$ Department of Semiology, Ethopathology and Medical Imaging, Faculty of Veterinary Medicine, \\ University of Agricultural Sciences and Veterinary Medicine Cluj-Napoca, Romania \\ *Corresponding author: cristian.dezdrobitu@usamvcluj.ro
}

Bulletin UASVM Veterinary Medicine 72(2) / 2015,

Print ISSN 1843-5270; Electronic ISSN 1843-5378

DOI:10.15835/buasvmcn-vm: 11335

\begin{abstract}
This study aimed to map the lymphatic drainage of the cranial thoracic mammary gland (T1) in clinically healthy domestic cats. The most important aspect was to identify the sentinel lymph node that drains the T1 mammary gland, leading to a new model of mammary tumor removal in the cat.

The study was conducted on 10 female's domestic cats. The applied methods of investigation were: radiographic indirect lymphography with contrast agent (Optiray 350), injecting a coloring agent (Evans blue dye) in vivo followed by subject euthanasia and stratigraphic and regional dissection. For each cat, have been supervised behavior and physiological parameters (i.e. pulse, breathing, temperature). The cats were kept in individual cages, and all experiments were performed one day later after the accommodation of each animal.

Drainage of the cranial thoracic mammary gland was found to be exclusively cranial in all subjects. The first lymph node station has been established that can be either the accessory axillary lymph node or the proper axillary lymph node when the former is missing. Taking into account internodal connections, the study has also underlined other lymph nodes involved in the drainage of the T1 mammary region.

The stratigraphic dissection method complements radiographic indirect lymphography with contrast agent, by uncovering features that the latter is unable to underline. Stratigraphic dissection can only be used as an experimental tool, but the radiographic indirect lymphography is a very good method for clinical use.
\end{abstract}

Keywords: cat, lymphography, lymphatic vessels, lymph nodes, mammary gland

\section{INTRODUCTION}

Feline mammary glands have lately become more and more frequently explored from an anatomical and histological point of view. This is due to their resemblance to human mammary glands, especially from a histological angle (Misdorp et al., 1999).

In veterinary medicine, breast cancer is one of the major diseases in mammary gland pathology. Studies in this field indicate that tumors of the mammary gland in the cat are ranked third from the point of view of the frequency of apparition and the major problem is that $85 \%$ of these tumors have a malign nature (Dorn et al., 1968; Lana et al., 2007; Misdorp et al.,1991; Morris and Dobson, 2001).

This study aimed to map a section of the lymphatic vascular system of the mammary glands in clinically healthy cats. Investigating the lymphatic system of the mammary glands offers clinicians and especially surgeons the various possibilities of mammary lymphatic drainage, knowing that any deviation from the pattern of drainage can signal the apparition of a cancerous pathology and that the lymphatic system is the main way for tumor metastasis. 


\section{MATERIALS AND METHODS}

This study was performed on 10 females common breed cats. In order to achieve the established goal and objectives were examined the T1 cranial thoracic mammary gland using two methods: the radiographic indirect lymphography with contrast agent and the method of injecting a coloring agent in vivo followed by stratigraphic and regional dissection. The biologic material was divided equally, 5 cats for the lymphography and 5 cats for the stratigraphic dissection.

The cats included in the lymphographic study and those included in the stratigraphic dissection study were of various ages and body weights. Their age varied between 2 to 6 years and the body weight between 1.5 to $4 \mathrm{~kg}$. The subjects were selected taking into account sexual maturity, with the purpose of having fully developed mammary gland from a physiological point of view. Both methods investigated the cranial thoracic mammary glands from a single side of the body.

Prior to each procedure neuroleptanalgesia in all examined subjects was performed. This was accomplished by intramuscular administration of $10 \%$ Acepromazine $(0.5 \mathrm{mg} / \mathrm{kg}$ body weight) and $10 \%$ Ketamine $(20 \mathrm{mg} / \mathrm{kg}$ body weight). After the induction of the general anesthesia, the region of the cranial thoracic mammary gland was clipped, shaved and disinfected with medicinal alcohol.

The method of radiographic indirect lymphography with contrast agent imposes the use of a contrast medium and of a radiological machine. In the case of our study, was used as contrast agent the product Optiray 350. The latter is an injectable, non-ionic, low osmolarity contrast medium. The radiographic images were performed with a fixed TEMCO GRx-01 type machine. The amount of $0.5 \mathrm{ml}$ of contrast agent was injected in the sub-areolar region and in the parenchyma of the mammary gland. The needle was inserted lightly at a subcutaneous level taking care to inject slowly, because the parenchyma of the cranial thoracic mammary gland is less developed than the rest of the mammary glands from the thoracic and abdominal regions. The radiological images were captured immediately after injecting the contrast agent, at 1 minute, 5 minutes and 10 minutes marks. The seriate radiological imaging allowed us to notice distribution pattern of the contrast agent from the parenchyma of the mammary gland into the lymph nodes that drain the lymph from the cranial thoracic mammary gland.

Has to be specified that the cats to which the lymphography method was used were entrusted by their owners and their consent for the applied maneuvers has been performed.

The regional and the stratigraphic dissection, preceded by in vivo injection of the coloring agent, imposed both a subcutaneous injection and an injection in the mammary parenchyma of the coloring substance. In this study was used Evans blue as coloring agent. This substance is a dark colored, hydrosoluble, dissolving well in both distilled water and saline solution, with tropism for the lymphatic system. We have used a concentration of $2.5 \%$ Evans blue and saline solution for the dilution. The $2.5 \%$ Evans blue injection was done in the sub-areolar region and in the mammary parenchyma, in the 4 cardinal points adjacent to the gland (cranially, caudally, laterally and medially). Each cranial thoracic mammary gland was injected with a total of $0.4 \mathrm{ml}$ of the coloring solution, $0.1 \mathrm{ml}$ in each point. For Due to the mammary gland chosen for the study - a mammary gland that is not so well developed by comparison with the rest of mammary gland pairs has been selected. The injection of the gland was repeated 24 hours after the first one, and the subjects were euthanized 48 hours later the first injection. The euthanasia was performed after the prior induction of a neuroleptanalgesia, by intravenous administration of the product $\mathrm{T}-61$. The protocol of the stratigraphic dissection followed the regional lymphatic drainage of the gland, trying to underline the lymphatic vessels that drain the gland, as well as its adjacent lymph nodes. For this purpose, was performed both a cranially and a caudally oriented dissection, to obtain a map of the lymphatic drainage of the cranial thoracic mammary gland (T1) as real as possible. The size of the lymph nodes was measured using an electronic caliper.

It has to be mentioned that the cats used for the method of in vivo injection of a coloring agent followed by stratigraphic and regional dissection, were brought by their owners in view of euthanasia for various reasons (aggressive behavior in the environment where they were raised, relocation of the owner to another country, impossibility of finding a new owner in due time for adoption). 


\section{RESULTS AND DISCUSSION}

On the radiographic images was noticed that the contrast medium has reached into the lymphatic channels, being thus distributed into the lymphatic plexus, leading to the uniform opacification of the cranial thoracic mammary gland's parenchyma in all of the five subjects. The propagation of the Optiray 350 contrast medium from the mammary parenchyma into the lymphatic vessels draining the cranial thoracic mammary gland led to obtaining two possibilities of lymphatic drainage, with regards to the number of main lymphatic vessels. One cat out of 5 presented two main lymphatic vessels draining the lymph and 4 subjects presented only a single main lymphatic vessel (Fig. 1).

With regards to the direction of the lymphatic drainage, the latter was exclusively cranial in all subjects. The radiographic images with the subjects in a latero-lateral and dorso-ventral decubitus and a latero-lateral and ventro-dorsal projection indicated the fact that the cranial thoracic mammary gland is drained by the cranial accessory axillary lymph node. The radiographs were obtained immediately after the injection of the contrast medium. This lymph node is part of the axillary lymph center and represents the first relay of the lymphatic drainage coming from the cranial thoracic mammary gland (Fig. 1).

The images obtained 10 minutes after the injection presented only a weak opacification of the lymphatic vessel and the drainage of the lymphatic center has not been observed (Fig. 2).

The method of in vivo injection of a coloring agent followed by stratigraphic and regional dissection offers much more complete data on the number of lymph nodes draining the cranial thoracic mammary gland. The dissection was performed both cranially and caudally to the mammary parenchyma. As in the case of the lymphographic method, the dissection demonstrated that the cranial thoracic mammary gland is drained exclusively in the cranial direction. It also underlined the fact that the first lymphatic relay is represented by the accessory axillary lymph node which was present in 4 out of 5 subjects. We noted a very good coloring of the accessory axillary lymph nodes which are located under the ventral border of the latissimus dorsi muscle and are palpable through the superficial muscles and the skin. Two lymph nodes were identified, one situated cranially and the other one caudally. The caudal lymph node measures $1 \mathrm{~cm}$ in length and $0.2-0.5 \mathrm{~cm}$ in width, while the cranial
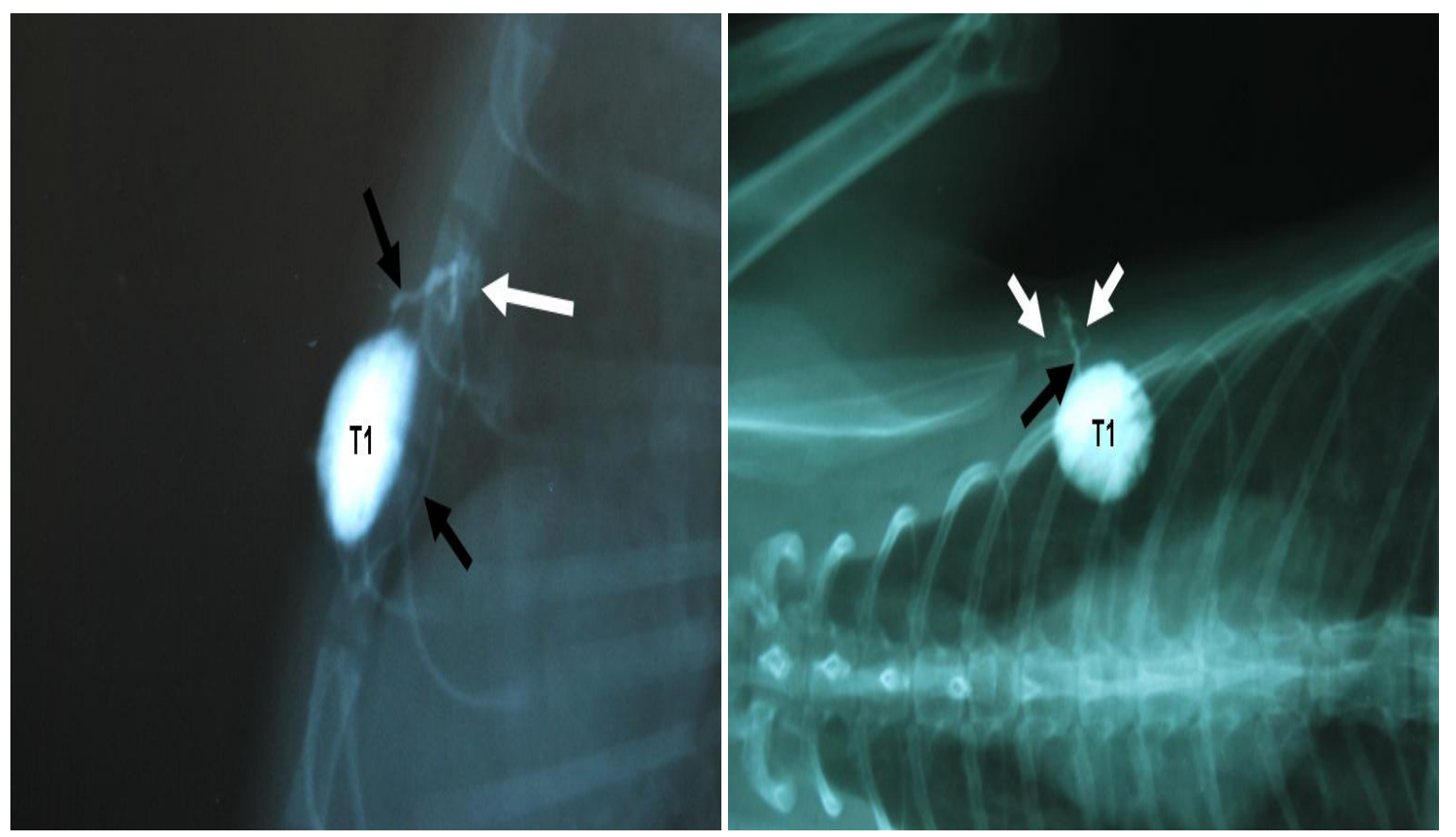

Fig. 1. Two main lymphatic vessels (black arrows - left image), one main lymphatic vessel (black arrow - right image) and accessory axillary lymph node (white arrow - left image and white arrows - right image). 
one is much smaller, registering about half the size of the caudal one (Fig. 3).

Continuing cranially with the dissection, was noted the lymphatic vessels emerging from the accessory axillary lymph node, that become afferent to the proper axillary lymph node. When isolating this lymph node, it presented a much smaller size than that of the accessory axillary lymph node, with the exception of a single case which we will later present in detail. The aspect referring to the dimensions of this lymph node confirm the fact that the accessory axillary lymph node which is sometimes composed of several bundles of lymph nodes is the actual main lymph node of the axillary lymph center. The proper axillary lymph node was located the between the teres major muscle and the pectoralis ascendens muscle, inside the angle between the lateral thoracic and the axillary veins, on the medial side of the arm (Fig. 4).

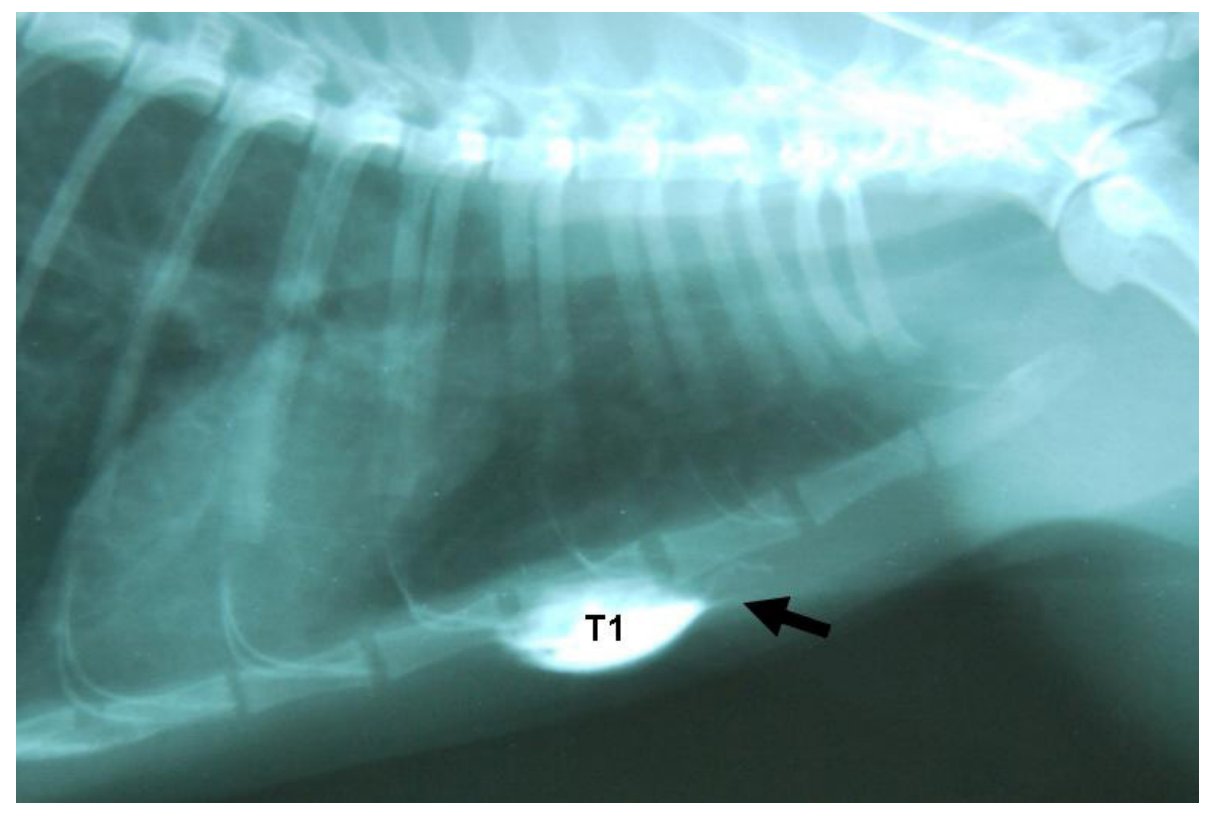

Fig. 2. The cranial thoracic mammary gland (10 minutes after the Optiray 350 injection).

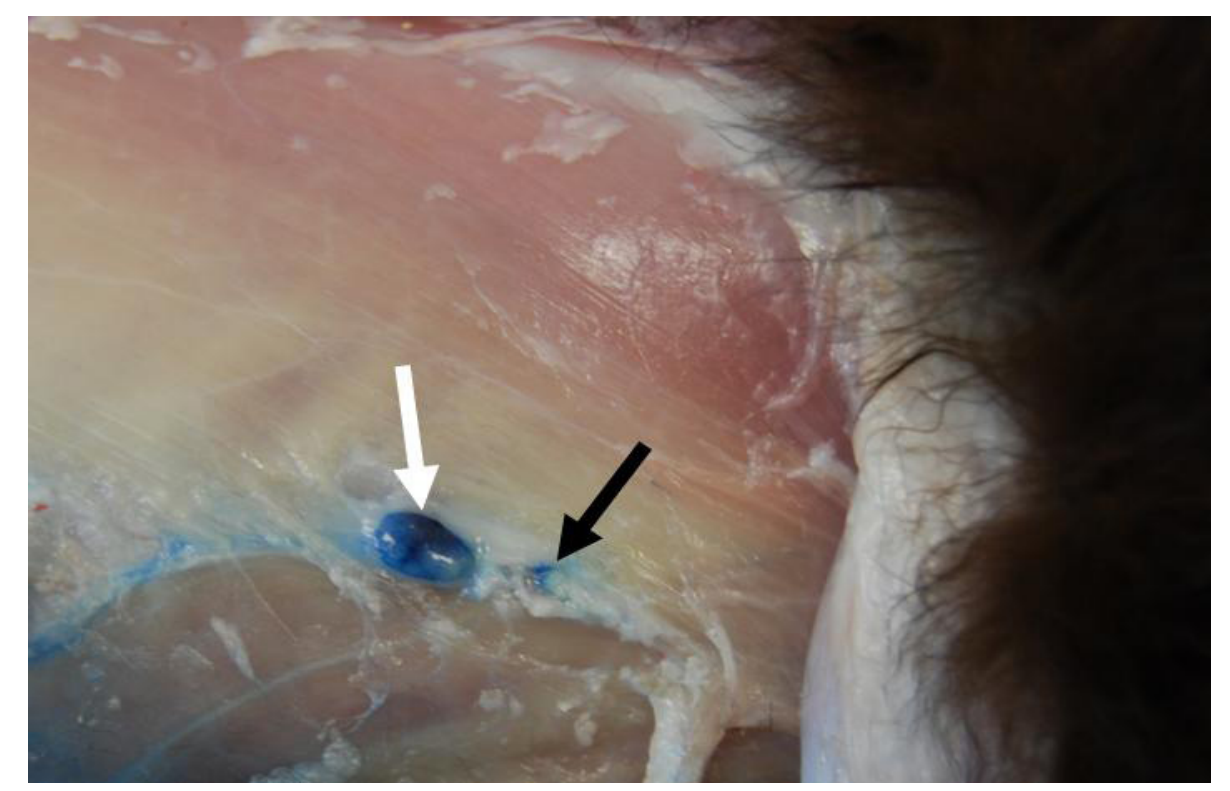

Fig. 3. The caudal accessory axillary lymph node (white arrow) and the cranial one (black arrow). 
As specified above, in one case was identified only the proper axillary lymph node. In this subject, labeled cat number 2, the proper axillary lymph node presents an elongated shape, measuring 1.5 $\mathrm{cm}$ in length and $0.4 \mathrm{~cm}$ in width. It can be emitted the hypothesis that the significantly larger size of this lymph node in this cat is due to the absence of the accessory axillary lymph node (Fig. 5).

Based on literature data and following the drainage direction of the lymph, the latter might reach the sternal lymph nodes, more precisely the cranial ones. The cranial sternal lymph node was identified in all of the examined cats and it presented a rather pronounced coloring. Its identification was possible after the opening of the thoracic cavity, at the ventral side of the internal thoracic vessels. Its dimensions are $1.2 \mathrm{~cm}$ in length and between 0.4-0.7 $\mathrm{cm}$ in width. It has to be highlighted that in one of the subjects, the cranial sternal lymph node is double (Fig. 6).

In order to obtain a map of the lymphatic drainage of the T1 gland as complete and as correct as possible, we have continued the dissection cranially. As it is a known, that the ventral cervical lymph node drains the pectoral region, the study was motivated to try to identify this lymph node and to assess its macroscopical level of Evans blue impregnation. This lymph node was found in all

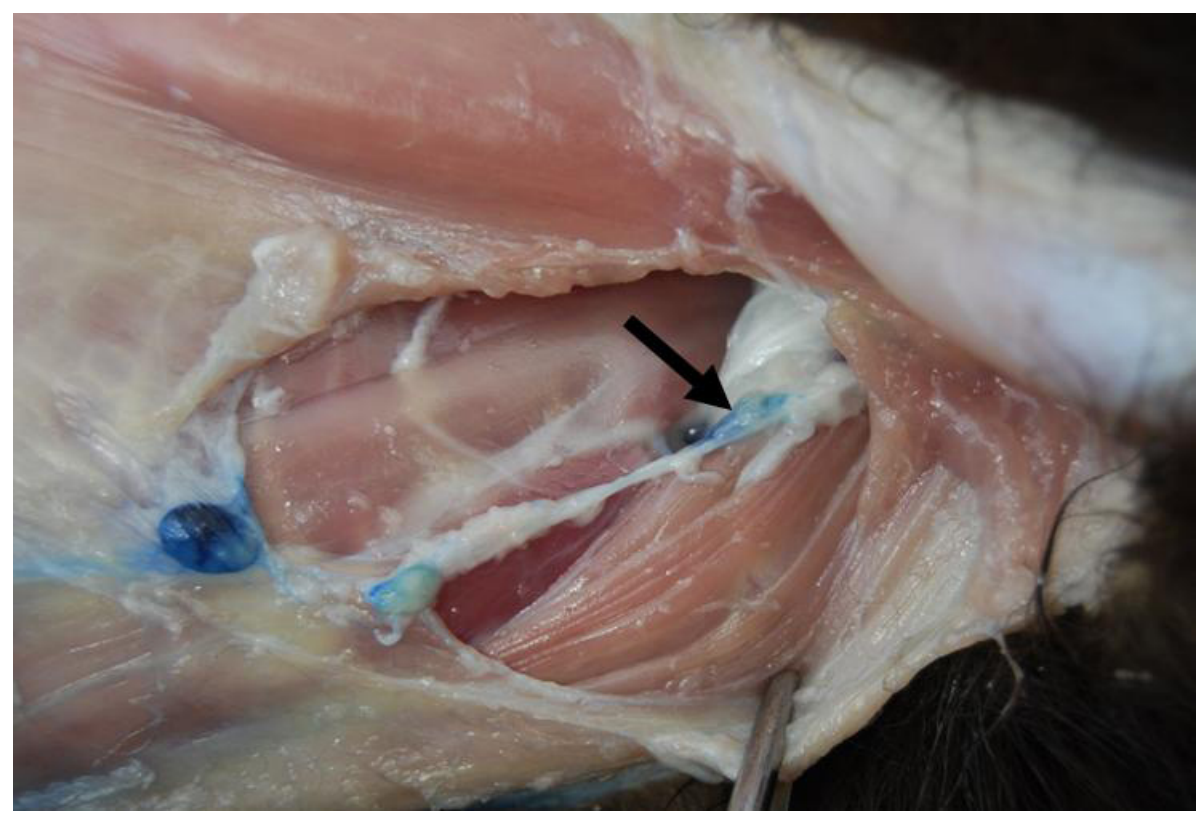

Fig. 4. The proper axillary lymph node.

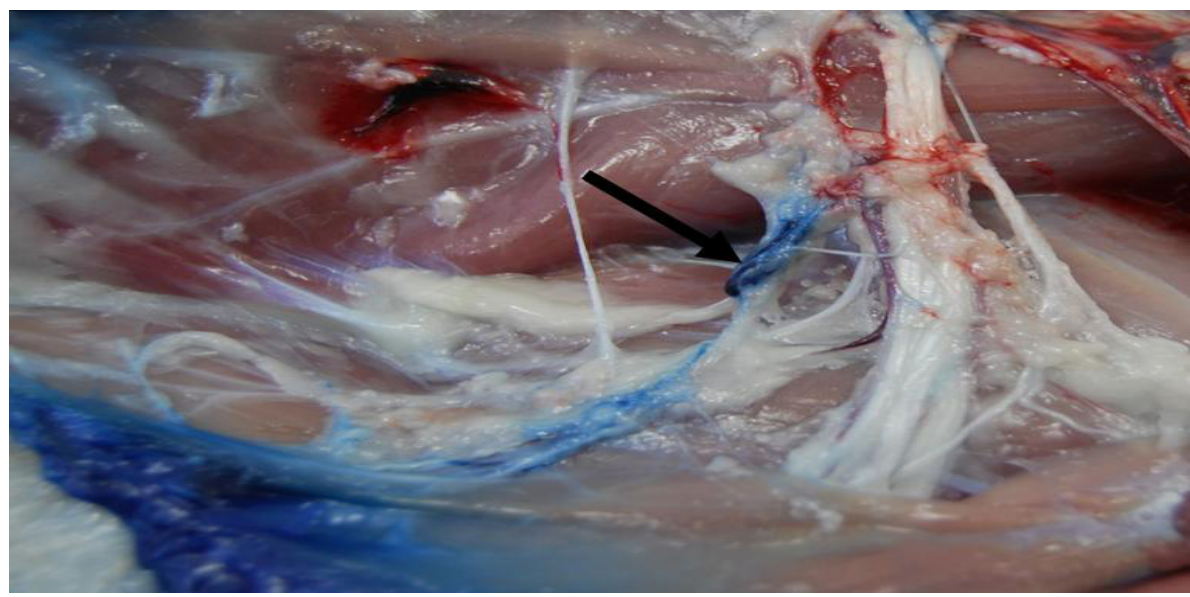

Fig. 5. The proper axillary lymph node in cat no.2. 
of the subjects, but with a coloration degree well below that of the lymph centers adjacent to the T1 cranial thoracic mammary gland. This lymph node was located close to the external jugular vein and the impregnation with Evans blue was visible after the removal of the adipose tissue surrounding it. Its shape is ovoid and its size varied from $0.8 \mathrm{~cm}$ to $1 \mathrm{~cm}$ (Fig. 7).

It has to be mentioned that some lymph nodes involved in the lymphatic drainage of the thoracic region, such as: the axillary lymph node of the first pair of ribs, the caudal sternal lymph nodes and the cranial epigastric lymph nodes, were not present in the examined subjects. From this point of view, the results confirm certain data from literature (Barone, 1996; Ratzlaff, 1970; Sisson and Grossman, 2004; Sugimura et al., 1956). The caudal deep cervical lymph nodes were present in only $60 \%$ of the subjects, but were not impregnated with Evans blue. Literature data affirm that these lymph nodes might be missing (Paşca et al., 2001; Sugimura et al., 1955).

Following the performed dissections, in any of the subjects lymphatic vessels linking the heterolateral cranial thoracic mammary glands were unable to be isolated.

To infirm the caudal drainage, the stratigraphic and regional dissection was also performed in this direction. Results show that the inguinofemoral and ilio-femoral lymph centers were not impregnated with Evans blue, which confirms once again the exclusively cranial drainage of the T1 cranial thoracic mammary gland.

The first lymphographic studies of the mammary lymphatic drainage in the cat were made in 2009 using Lipiodol UltraFluid as contrast agent (Papadopoulou et al., 2009; Patsikas et al., 2010).

In the lymphographic method's case, the exclusively cranial drainage of the cranial thoracic

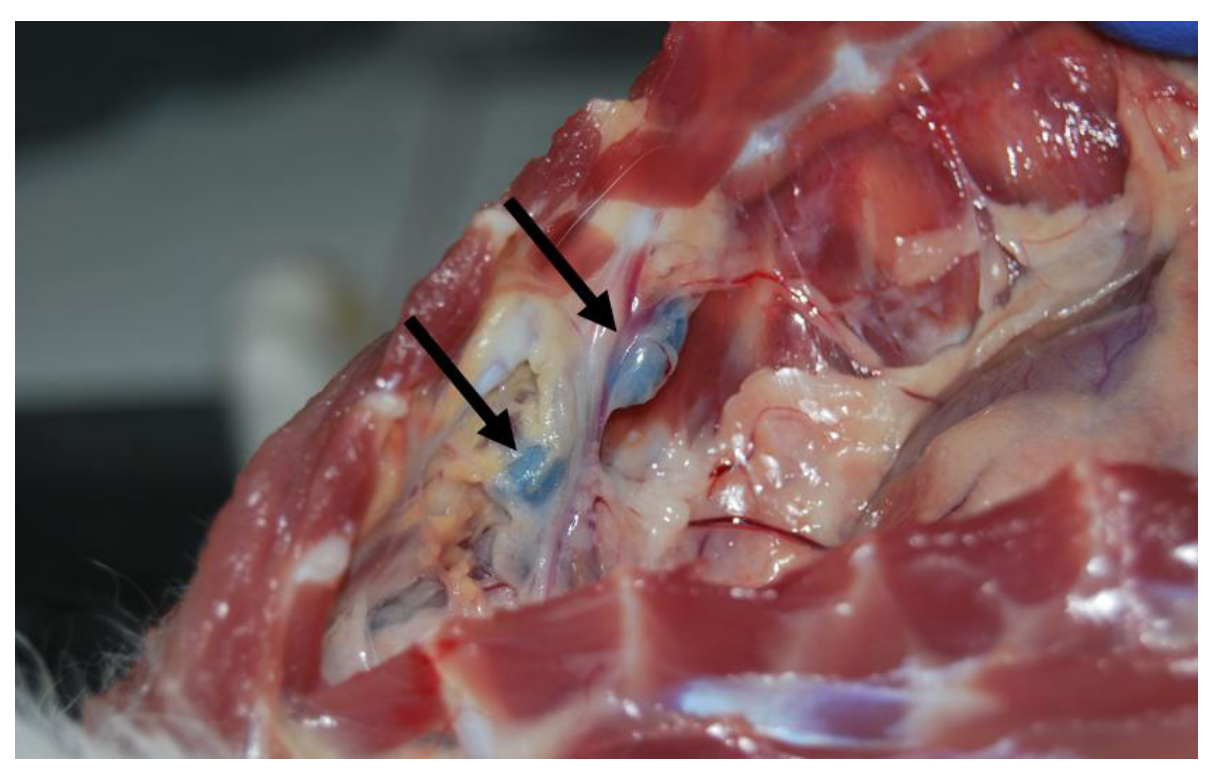

Fig. 6. Double cranial sternal lymph node.

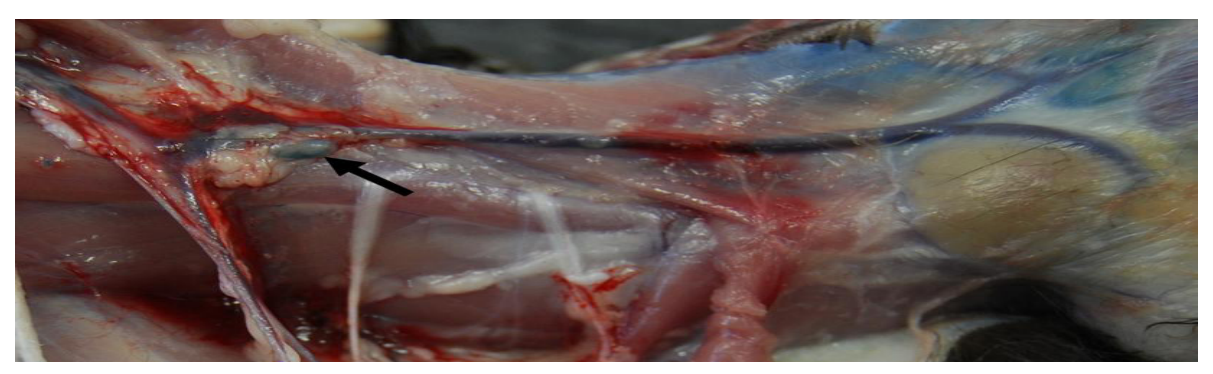

Fig. 7. Ventral cervical lymph node. 
mammary gland and the localization of the first lymphatic relay, namely the cranial accessory axillary lymph node, in all cases was proven. The latter was found located in-between the third and the fourth sternebrae, in compliance to literature data (Sugimura et al., 1956). Some authors ascertain that the accessory axillary lymph node is double or triple, while in this study has been identified via the lymphographic method only a single one (Papadopoulou et al., 2009).

Investigating the lymphatic system by injecting colorant agents with tropism for the lymphatic tissue has been known and applied by several authors. Most studies performed by various authors focus on the mammary gland in the bitch, sometimes using the general term of carnivores (Patsikas and Dessiris, 1996a, 1996b). Researchers such as Baum (1918), Stalker and Schlotthauer (1936), Ruberte et al. (1990), Sautet et al. (1992), Stan (2009), have injected Berlin blue, India ink and Evans blue in the mammary glandular tissue in the bitch, thus highlighting by anatomic dissection the mammary lymphatic drainage (Baum, 1918; Sautet et al., 1992; Stalker şi Schlotthauer, 1936; Stan, 2009).

Research of the mammary lymphatic drainage in the cats was performed by injection of a blue coloring agent on cadavers, followed by their dissection (Sugimura et al., 1956, 1958, 1960; Vollmerhaus and Roos, 1997). Then another method was applied, of injection of a coloring agent on live cats, followed by their euthanasia and the highlighting of the mammary lymphatic drainage by dissection (Raharison and Sautet, 2007, 2006).

This study was applied using live cats, in compliance with some authors stating that this type of assessment is much closer to the truth, because it is performed in physiological conditions of lymph streaming (Raharison and Sautet, 2006).

Regarding the obtained results after the assessment of the cranial thoracic mammary gland by stratigraphic and regional dissection, it can be stated that all subjects presented an exclusively cranial lymphatic drainage through the axillary lymph center (Raharison and Sautet, 2007, 2006; Sugimura et al., 1960; Vollmerhaus and Roos, 1997). The first relayed reached by the lymph is the cranial accessory axillary lymph node. The results obtained for this gland show that both the proper axillary lymph node and the cranial sternal lymph node play a part in the lymphatic drainage of the T1 gland. There are authors confirming the aforementioned aspects (Barone, 1996; Raharison and Sautet, 2007, 2006).

Some authors assert that they have identified the axillary lymph node of the first pair of ribs, but on the subjects of this study, this element was not identified. It is supposed that they have identified it in a very small percentage (Meier, 1989; Raharison and Sautet, 2007, 2006; Sugimura et al., 1956).

Even if the literature makes no reference to the ventral cervical lymph node, must be mentioned that the identified lymph nodes in all our subjects were weakly colored. This aspect makes it responsible for the cranial thoracic mammary gland drainage.

\section{CONCLUSION}

This study has proven both by radiographic indirect lymphography with contrast agent and by the method of in vivo injection of a coloring agent followed by stratigraphic and regional dissection the fact that the cranial thoracic mammary gland in the domestic cat presents an exclusively cranial type of drainage. The sentinel lymph node can be represented by the cranial accessory axillary lymph node or by the proper axillary lymph node, when the former is missing. The present study highlights the variability of the lymphatic circulatory system by its results with regards to both the number of the lymphatic vessels and the presence or absence of certain lymph nodes in some subjects. The internodal connection is very important, because in case of cancer affecting the cranial thoracic mammary gland, one must consider not only the sentinel lymph node, but also the rest of the lymph centers involved in the drainage of this gland lymph centers previously mentioned in this paper. It is of high clinical importance that there are not lymphatic connections between the heterolateral cranial thoracic mammary glands. The method of stratigraphic dissection completes that which the radiographic indirect lymphography with contrast agent was not highlighted, offering important data on the number, the size and more importantly on the topography of the lymph nodes. The fact that the dissection method allowed locating the topography of all of the lymph nodes involved in the drainage of the cranial thoracic mammary gland must be taken into account, because this is a very important aspect for the surgery applied on this segment. The stratigraphic dissection can 
only be used with experimental purposes, but the radiographic indirect lymphography is a very good and quick method that can be used in clinical work. The change of the pattern and of the aspect of the lymphatic map that performed through this study can have pathological implications of the lymphatic drainage. Such a change in pattern can be visible through radiological imaging. An important aspect of the previous statement is the fact that the used contrast agent did not alter the health status of the subjects.

This study was approved by the Bioethical Board of the Faculty of Veterinary Medicine of Cluj-Napoca, Romania.

\section{REFERENCES}

1. Barone R (1996). Anatomie comparée des mammifères domestiques.Tome V, Angiologie. Vigot, 687-879.

2. Baum H (1918). Das lymphgefa lystem des hundes. Arch Wiss Pract.Tierhk, 44, 521- 650.

3. Dorn CR, Taylor D, Schneider R, Hibbard H and Klauder RM (1968). Survey of animal neoplasms in Alameda and Contra Costa counties California II. Cancer morbidity in dogs and cats from Alameda country. J Natl Cancer Inst 40, 307-318.

4. Lana S, U'ren L, Plaza S, Elmslie R, Gustafson D, Morley P, Dow $S$ (2007). Continuous low-dose oral chemotherapy for adjuvant therapy of splenic hemangiosarcoma in dogs. J Vet Intern Med 21, 764-769.

5. Meier A (1989). Zur deskriptiven Anatomie der tastbaren Lymphoknoten der Hauskatze. Diss Med Vet Munchen.

6. Misdorp W, Else RW, Helmén E, Lipscomb TP (1999). Histological Classification of Mammary Tumors of the Dog and Cat. Washington, Armed Forces Institute of Pathology and World Health Organization.

7. Misdorp W, Romijin A, Hart AA (1991). Feline mammary tumors: a case control study of hormonal factors. Anticancer Res 11, 1793-1798.

8. Morris J, Dobson J (2001). Mammary gland. In: Small Animal Oncology, Blackwell Science Ltd, London, 184191.

9. Papadopoulou PL, Patsikas MN, Charitanti A, Kazakos GM, Papazoglou LG, Karayannopoulou M, Chrisogonidis I, Tziris N, Dimitriadis A (2009). The Lymph Drainage Pattern of the Mammary Glands in the Cat: A Lymphographic and Computerized Tomography Lymphographic Study. Anat Histol Embryol 38:292-299.

10. Pașca C, Papuc I, Mireșan V (2001). Anatomie comparată și histologie - Aparatul cardiovascular. Vol. II. Risoprint, Cluj-Napoca, 130-229.

11. Patsikas MN, Papadopoulou L, Charitanti A, Kazakos GM, Soultani CB, Tziris E, Tzegas I, Jakovljevic S, Savas I, Stamoulas KG (2010). Computed tomography and radiographic indirect lymphography for visualization of mammary lymphatic vessels and the sentinel lymph node in normal cats. Veterinary Radiology \& Ultrasound 51(3): 299-304.

12. Patsikas MN, Dessiris A (1996). The lymph drainage of the mammary glands in the bitch: a lymphographic study. Part II: The 3rd mammary gland. Anat Histol Embryol 25:139143.

13. Patsikas MN, Dessiris A (1996). The lymph drainage of the mammary glands in the bitch: a lymphographic study. Part I: The 1st, 2nd, 4th and 5th mammary glands. Anat Histol Embryol 25:131-138.

14. Raharison F, Sautet J (2006). Lymph drainage of the mammary glands in female cats. J Morphol 267:292299.

15. Raharison F, Sautet J (2007). The Topography of the Lymph Vessels of Mammary Glands in Female Cats. Anat Histol Embryol 36:442-452.

16. Ratzlaff MH (1970). The superficial lymphatic system of the cat. Lymphology. 3:151- 159.

17. Ruberte J, Sautet JY, Gine JM, Lopez C, Rodriguez A (1990). Topography of the lymphatic collecting ducts of the mammary glands of the dog. Anat Histol Embryol 19:347358.

18. Sautet JY, Ruberte J, Lopez C, Gine JM, Ordonez G, Cingia A (1992). Lymphatic system of the mammary gland in the dog: an approach of the surgical treatment of malignant mammary tumors. Canine Pract 17:30-33.

19. Sisson S, Grossman ID (2004). Anatomia de los animales domesticos. Tomo II. Masson, Barcelona, 1811-1831.

20. Stalker LK, Schlotthauer CF (1936) Neoplasms of the mammary gland in the dog. The surgical treatment of mammary tumors. Report of two cases in study of the lymphatic drainage of mammary glands. North Am Vet 17:33-43.

21. Stan F (2009). Studiul sistemului limfatic superficial din regiunea mamelelor la cățea. Teză de doctorat, FMV ClujNapoca.

22. Stan F (2009). Study on the Lymphatic Vascularisation of the Cranial Thoracic Mammary Gland (T1) in Bitch. Bulletin of the University of Agricultural Sciences and Veterinary Medicine, Cluj-Napoca, 66(1):114.

23. Sugimura M, Kudo N, Takahata (1960). Studies on the lymphonodi of cats. V. Lymphatic drainage from the peritoneal and pleural cavities. Jap J Vet Res 8:35-46.

24. Sugimura M, Kudo N, Takahata (1958). Studies on the lymphonodi of cats. III. Macroscopical observations on the lymphonodi in the abdominal and pelvic cavities. Jap J Vet Res 6:69-88.

25. Sugimura M, Kudo N, Takahata (1956). Studies on the lymphonodi of cats. II. Macroscopical observations on the lymphonodi of the body surfaces, thoracic and pelvic limbs. Jap J Vet Res 4:101-112.

26. Sugimura M, Kudo N, Takahata (1955). Studies on the lymphonodi of cats. I. Macroscopical observations on the lymphonodi of heads and necks. Jap J Vet Res 3:90-105.

27. Vollmerhaus B, Roos H (1997). On the regional lymph nodes of mammary gland in the domestic cat - a summarizing study. Kleintierpraxis 42:221-229. 